\title{
Desain Konten Pendidikan Warisan Budaya 4.0 bagi Warga 'Aisyiyah Kota Surakarta pada Webpage Lembaga Kebudayaan Pimpinan Daerah 'Aisyiyah Kota Surakarta
}

\author{
Mimi Savitri, Andi Putranto \\ Departemen Arkeologi, Fakultas Ilmu Budaya, Universitas Gadjah Mada \\ Posel: mimi.savitri@ugm.ac.id
}

\begin{abstract}
Cultural Institution of Regional Leaderships of 'Aisyiyah in Surakarta has not been able to carry out its programs including cultural heritage education. The webpage of the Cultural Institution in the website of the Regional Leadership of Aisyiyah in Surakarta should be used as an effective medium for cultural heritage education in the 4.0 era. Based on the problem above, this community service aims to provide cultural heritage education to members of 'Aisyiyah by using internet. The questions raised in this community service:1.»Which part of the history of Surakarta which is important used as cultural heritage education material in 4.0 era for 'Aisyiyah members in Surakarta?" And "How were the efforts made to determine the design and content of the webpage which was easy to understand by 'Aisyiyah members?" The method used is to interview 'Aisyiyah members to determine the right place of Surakarta for the webpage. Then some discussions were also carried out by the community service team to produce attractive and effective content designs which was in accordance with the needs of 'Aisyiyah members in Surakarta. The results of the interviews and discussions demonstrate that the Surakarta Palace and the Surakarta Grand Mosque as the focus of the webpage of the Cultural Institution. Furthermore, the selected building's elements are displayed in attractive photographs with popular scientific language so that the content displayed is easy to understand.
\end{abstract}

Keywords: education, heritage, Regional Leadership of Aisyiyah Surakarta, Cultural Institution, webpage, website

\begin{abstract}
Abstrak
Lembaga Kebudayaan Pimpinan Daerah 'Aisyiyah Kota Surakarta merupakan bagian dari organisasi perempuan 'Aisyiyah yang dibentuk untuk menyelesaikan persoalan budaya masyarakat Kota Surakarta. Pada kenyataannya, Lembaga Kebudayaan ini belum dapat menjalankan programnya secara maksimal, terutama dalam hal memberikan pendidikan warisan budaya kepada warganya. Padahal, pendidikan warisan budaya penting diberikan untuk mempertegas identitas warga 'Aisyiyah beserta generasi pada masa mendatang. Webpage Lembaga Kebudayaan yang ada pada website Pimpinan Daerah 'Aisyiyah Kota Surakarta sebagai media efektif untuk pendidikan warisan budaya pada era digital 4.0 ini belum digunakan sama sekali oleh lembaga tersebut. Pengabdian yang dilakukan ini berusaha untuk menentukan bagian mana dari Kota Surakarta yang penting untuk dijadikan konten webpage Lembaga Kebudayaan serta menciptakan desain yang menarik dan efektif untuk pendidikan warisan budaya bagi warga 'Aisyiyah pada era digital ini agar mereka paham dan sadar terhadap tinggalan budaya kota mereka. Pengabdian ini bertujuan mengaktifkan webpage Lembaga Kebudayaan Pimpinan Daerah 'Aisyiyah kota Surakarta. Webpage pada website merupakan media yang
\end{abstract}


efektif dan penting untuk pembelajaran, khususnya tentang kebudayaan. Wawancara terhadap warga 'Aisyiyah serta diskusi-diskusi dilakukan oleh tim pengabdian untuk menghasilkan desain konten yang menarik dan efektif bagi warga 'Aisyiyah Kota Surakarta. Wilayah Keraton Surakarta, khususnya Keraton Kasunanan Surakarta serta Masjid Agung Surakarta, merupakan fokus dari konten webpage pada website Lembaga Kebudayaan yang di-link-kan dengan website Pimpinan Daerah 'Aisyiyah Kota Surakarta. Elemen-elemen bangunan terpilih ditampilkan dalam bentuk foto yang menarik dengan bahasa ilmiah populer agar konten yang ditampilkan mudah dipahami.

Kata Kunci: pendidikan warisan budaya, Pimpinan Daerah 'Aisyiyah kota Surakarta, Lembaga Kebudayaan 'Aisyiyah Kota Surakarta, webpage, website

\section{Pendahuluan}

Lembaga Kebudayaan merupakan satu-satunya lembaga di 'Aisyiyah yang dibentuk untuk meningkatkan perhatian terhadap persoalan budaya yang memengaruhi kepentingan masyarakat dengan cara mengembangkan budaya Islam atau budaya yang muncul karena adanya pengaruh Islam. Upaya tersebut dilakukan untuk mendorong dan membangkitkan fitrah kemanusiaan serta mendekatkan manusia pada Sang Pencipta. ${ }^{1}$ 'Aisyiyah sebagai organisasi perempuan Persyarikatan Muhammadiyah, yang didirikan oleh Nyai Siti Walidah bersama dengan suaminya KH Ahmad Dahlan, telah memberikan kontribusi yang besar bagi perkembangan kehidupan perempuan Indonesia sejak awal abad ke-20 (Hadirin dkk 2001). Visi organisasi 'Aisyiyah mengarah pada penguatan dan pengembangan dakwah amar makruf nahi mungkar secara lebih berkualitas menuju masyarakat madani atau masyarakat Islam yang sebenar-benarnya. ${ }^{2}$ Berkaitan dengan misi tersebut, organisasi itu membentuk beberapa majelis dan sebuah lembaga agar program kerja yang telah dicanangkan dapat berjalan secara efektif. Untuk mencapai visi tersebut, salah satu misi 'Aisyiyah adalah meningkatkan pendidikan, mengembangkan kebudayaan, memperluas ilmu pengetahuan dan teknologi, serta menggairahkan penelitian. ${ }^{3}$

Alasan lain upaya pengembangan budaya tersebut adalah demi keberlangsungan budaya yang akan kita wariskan kepada generasi mendatang. Oleh karena itu, budaya yang berkarakter serta berkualitas sangat penting untuk dikembangkan (Aucklair dan Fairclough, 2015:1-2). Simanjuntak (2012:7) menyatakan bahwa karakter itu tumbuh dari masa lampau sebagai perwujudan nilai-nilai kehidupan yang diturunkan dari satu generasi ke generasi berikutnya. Hal tersebut berguna untuk mempertegas jati diri dan identitas anak bangsa karena memiliki budaya tinggi, bersifat religius, serta berwawasan kebangsaan.

Sehubungan dengan tugas Lembaga Kebudayaan itu, Lembaga Kebudayaan Pimpinan Daerah 'Aisyiyah Kota Surakarta yang berada di bawah struktur organisasi

1 http://kota-surakarta.aisyiyah.or.id/id/page/lembaga-kebudayaan.html diunduh pada 6 Februari 2019.

2 http://www.muhammadiyah.or.id/id/content-199- det-aisyiyah.html diunduh pada 6 Februari 2019.

3 http://www.muhammadiyah.or.id/id/content-199-det-aisyiyah.html diunduh pada 6 Februari 2019. 
Pimpinan Daerah 'Aisyiyah Kota Surakarta ${ }^{4}$ memiliki kewajiban untuk mengembangkan serta mempertahankan keberadaan kebudayaan yang ada di Kota Surakarta. Upaya tersebut penting dilakukan karena perkembangan kota yang dipengaruhi oleh perkembangan ekonomi telah mengancam keberadaan bangunan-bangunan bersejarah di Kota Surakarta sebagai bagian dari kebudayaan kota. Bangunan-bangunan tersebut, di antaranya, adalah Keraton Kasunanan Surakarta dan Masjid Agung Surakarta. Bangunan tersebut memiliki arti penting yang tidak dapat diperbarui lagi keberadaannya (Bandarin dan Oers, 2015:1; Putranto, 2016:3), namun terancam keberadaannya akibat modernisasi.

Keterancaman warisan budaya yang terjadi di Kota Surakarta perlu untuk segera ditanggulangi. Apabila masalah keterancaman warisan budaya tidak diselesaikan, dapat mengakibatkan hilangnya identitas masyarakat, termasuk warga 'Aisyiyah Kota Surakarta yang juga merupakan anggota dari Lembaga Kebudayaan Pimpinan Daerah 'Aisyiyah Kota Surakarta. Kehilangan identitas mengakibatkan kehilangan kebanggaan mereka sebagai warga Kota Surakarta yang berbudaya tinggi.

Kota Surakarta memiliki nilai kesejarahan yang tinggi karena kota ini dahulu pernah menjadi ibu kota Kerajaan Mataram Islam yang besar dan kuat pada abad ke-17. Kota ini kemudian menjadi ibu kota Kerajaan Surakarta atau disebut pula dengan Kasunanan Surakarta pada abad ke-18 hingga awal abad ke-20 (Savitri, 2015). Keberhasilan sebuah kota untuk mempertahankan kontinuitas budaya berkaitan dengan tata letak ibu kota kerajaan Islam di Jawa ini masih dapat dilihat keberadaannya hingga saat ini di Kota Surakarta. Hal ini berbeda dengan pembentukan kota lainnya seperti Yogyakarta. Kota Yogyakarta ditetapkan menjadi ibu kota kerajaan oleh Pangeran Mangkubumi yang kemudian menjadi Raja Yogyakarta dengan gelar Hamengkubuwana I di tempat yang dahulu merupakan sebuah hutan yang dikenal dengan Hutan Beringan (Darmosugito, 1956:14). Oleh karena itu, identitas budaya warga 'Aisyiyah Kota Surakarta penting untuk dikonstruksi dan diperkuat sebagai komunitas yang terhubung melalui pengalaman sosial budaya serta religi dalam lingkup geografis tertentu, dalam hal ini Kota Surakarta. Tidak hanya itu, upaya tersebut juga penting sebagai bentuk pelestarian warisan budaya sebagaimana yang tercantum pada Undang-Undang Cagar Budaya No. 11 Tahun 2010 (Anonim, t.t.; Putranto 2018:160).

Lembaga Kebudayaan Pimpinan Daerah 'Aisyiyah Kota Surakarta, dalam kenyataannya, belum dapat menjalankan program yang menjadi tugas dan kewajibannya itu secara optimal demi kemajuan warga 'Aisyiyah di Kota Surakarta. Website yang seharusnya dapat digunakan untuk mendukung program-program Lembaga Kebudayaan secara efektif, belum dimanfaatkan. Hal ini tampak pada pengamatan terhadap website Pimpinan Daerah 'Aisyiyah Kota Surakarta yang belum menampilkan informasi yang bertujuan memberikan pendidikan warisan budaya kepada warga 'Aisyiyah secara

4 Pimpinan Daerah 'Aisyiyah Kota Surakarta merupakan organisasi masyarakat yang diakui oleh Pemerintah Kota Surakarta. Hal itu terbukti dengan adanya bantuan dana bantuan sebesar Rp10.000.000,00/tahun untuk pelaksanaan program-program organisasi tersebut. Selain itu, kerja sama intensif juga telah dilakukan antara Pemerintah Kota Surakarta dan beberapa majelis yang ada di Pimpinan Daerah 'Aisyiyah Kota Surakarta, di antaranya, adalah penanganan penyakit TBC, pelindungan HAM, dan pendidikan. 
maksimal. Padahal, pada abad ke-21 ini, atau yang dikenal dengan era Revolusi Industri 4.0, internet sebagai bagian dari teknologi digital merupakan hal yang tidak dapat dihindari pemakaiannya dalam kehidupan manusia sehari-hari dan teknologi tersebut telah mendominasi kehidupan manusia saat ini. Hal ini dibuktikan dari jumlah pengguna internet di Indonesia saat ini, yaitu 143,26 juta jiwa dari total populasi penduduk Indonesia 262 juta orang. Demikian pula halnya dengan ukuran komputer sebagai sarana untuk mengakses internet yang semakin kecil-hanya sekepalan tangan-dalam bentuk ponsel pintar yang terhubung dalam berbagai jaringan di seluruh dunia ini merupakan langkah awal menuju Revolusi Industri 4.0. Dengan demikian, apabila dapat menggunakan ponsel pintar secara cerdas, tidak hanya untuk WhatsApp atau Facebook, warga 'Aisyiyah Kota Surakarta dapat menjadi warga yang pintar karena 'dunia' telah ada di genggamannya. Menjadi warga pintar merupakan hal yang penting sebagai pendukung aktif Kota Surakarta sebagai kota pintar atau smart city sebagaimana misi Pemerintah Kota Surakarta untuk mencapai kesejahteraan masyarakat melalui pemanfaatan IT dalam program-program Pemerintah Kota Surakarta (Aosgi 2018) ${ }^{5}$

Berkaitan dengan hal tersebut, salah satu hal yang dapat dilakukan warga 'Aisyiyah Kota Surakarta untuk menjadikan dirinya pintar adalah dengan mempelajari keberadaan warisan budaya melalui teknologi yang ditawarkan oleh ponsel pintar mereka. Hal ini sesuai dengan tiga faktor pembelajaran pada Revolusi Industri 4.0, yaitu virtual, personalisation, dan open. Sehubungan dengan hal tersebut, penting bagi Lembaga Kebudayaan Pimpinan Daerah Kota Surakarta untuk mendesain webpage yang sesuai dengan kebutuhan mereka untuk mempelajari warisan budaya, dalam hal ini Kota Surakarta, di manapun dan kapan pun. Hal ini sesuai dengan perkembangan teknologi terkini yang berkaitan dengan era digital, khususnya internet di bidang arkeologi, yang melalui internet itulah arkeolog mampu menciptakan pengalaman masa lalu bagi masyarakat awam (Morgan dan Eve, 2012:521).

Program pengenalan yang juga merupakan pembelajaran fokus pada proses daripada hasil. Hal ini nantinya diharapkan tidak hanya dapat membuka potensi baru bagi masyarakat untuk tertarik mempelajari warisan budaya melalui internet yang kini mulai dekat dengan kehidupan sehari-hari mereka, namun juga dapat menggunakan internet untuk keperluan lainnya yang bermanfaat bagi mereka. Hal ini penting untuk membangun kesadaran baru pada masyarakat untuk memahami sejarah kotanya melalui tinggalan budaya berupa bangunan bersejarah.

Dengan mempertimbangkan hal tersebut, pengabdian masyarakat ini dilakukan dengan cara membuat desain webpage secara offline terlebih dahulu, yang kemudian di-online-kan. Selanjutnya, website dihubungkan pada website Pimpinan Daerah 'Aisyiyah Kota Surakarta pada menu a ta u webpage Lembaga Kebudayaan. Sebaliknya, website Pimpinan Daerah 'Aisyiyah Kota Surakarta mencantumkan alamat website Lembaga Kebudayaan. Desain konten webpage ini difokuskan pada upaya mendidik warga 'Aisyiyah Kota Surakarta untuk memahami sejarah Kota Surakarta sejak kota didirikan pada $1745 \mathrm{M}$ hingga sebelum kemerdekaan.

Sehubungan dengan latar belakang yang dikemukakan di atas maka pertanyaan yang diajukan pada pengabdian ini adalah sebagai berikut.

- Bagian mana dari sejarah Kota Surakarta yang penting untuk dijadikan sebagai

5 http://surakarta.go.id/?p=12070 diunduh pada tanggal 19 Oktober 2019 
materi pendidikan warisan budaya 4.0 bagi warga 'Aisyiyah Kota Surakarta?

- Bagaimana upaya yang dilakukan untuk menentukan desain konten webpage yang tepat sehingga mudah dimengerti oleh ibu-ibu yang menjadi warga 'Aisyiyah Kota Surakarta?

Pertanyaan tersebut diajukan karena penting untuk meningkatkan kesadaran warga 'Aisyiyah Kota Surakarta terhadap warisan budaya, terutama yang terkait dengan keberadaan warisan budaya dari leluhur mereka.

Pendidikan warisan budaya 4.0 yang dilakukan bagi warga 'Aisyiyah ini memiliki tujuan jangka pendek dan jangka panjang. Tujuan jangka pendek kegiatan ini adalah mengoptimalkan peran dan fungsi website organisasi. Tujuan lainnya adalah meningkatkan pengetahuan dan kesadaran ibu-ibu warga 'Aisyiyah di Kota Surakarta terhadap warisan budaya yang mereka miliki.

Selain tujuan jangka pendek, kegiatan ini mempunyai tujuan jangka panjang sesuai dengan konsep pelestarian Cagar Budaya sebagaimana terdapat dalam Undang-Undang Cagar Budaya No. 11 Tahun 2010. Cagar Budaya di Kota Surakarta perlu dijaga kelestariannya karena dapat menjadi ciri khas atau identitas warga Kota Surakarta serta dapat membangkitkan kebanggaan warga kota saat ini serta pada masa mendatang. Cagar budaya yang terjamin keaslian serta keunikannya karena kesadaran masyarakat menjadi hadiah yang istimewa bagi generasi mendatang.

Tujuan lain dari kegiatan ini adalah membuka wawasan ibu-ibu warga 'Aisyiyah Kota Surakarta tentang manfaat dari ponsel pintar untuk meningkatkan potensi dirinya sehingga menjadi masyarakat yang tidak hanya pintar dalam bidang sejarah, namun juga bidang lainnya seperti ekonomi, misalnya untuk memasarkan barang dagangan mereka. Agar tujuan jangka pendek dan panjang tersebut dapat tercapai maka dilakukan beberapa cara seperti diskusi, survei, serta wawancara pada pengabdian masyarakat yang dilakukan dengan dukungan dana dari Fakultas Ilmu Budaya, Universitas Gadjah Mada.

\section{Pelaksanaan Pengabdian}

\section{Tahap awal}

Pengabdian ini dilakukan dalam beberapa tahap, yaitu tahap awal, pelaksanaan, dan akhir. Tahap awal dilakukan dengan cara melakukan pendekatan kepada pengurus Pimpinan Daerah 'Aisyiyah Kota Surakarta. Pendekatan secara organisasional penting dilakukan kepada pengurus Pimpinan Daerah 'Aisyiyah Kota Surakarta serta Lembaga Kebudayaan Pimpinan Daerah 'Aisyiyah Kota Surakarta untuk penjajakan terhadap peluang terlaksananya kegiatan ini sekaligus untuk memperoleh izin secara kelembagaan bagi terlaksananya program pengabdian ini. Selanjutnya, dilakukan diskusi secara intern antartim pengabdian masyarakat serta diskusi antara tim pengabdian masyarakat dan narasumber serta webdesigner terkait dengan kemungkinan untuk melakukan pendidikan warisan budaya melalui website.

Sesuai dengan masalah yang diajukan pada pengabdian ini maka langkah pertama untuk menjawab pertanyaan yang diajukan adalah menentukan bagian mana dari sejarah Kota Surakarta yang dijadikan sebagai materi pendidikan warisan budaya 4.0. Cara ini dilakukan dengan melakukan wawancara terhadap Ibu $\mathrm{Hj}$. Sukasni selaku Ketua 
Lembaga Penelitian dan Pengembangan Pimpinan Daerah 'Aisyiyah Kota Surakarta serta tiga orang pengurus Lembaga Kebudayaan Pimpinan Daerah 'Aisyiyah Surakarta. Wawancara dilakukan secara terbuka untuk mengetahui sejauh mana pengetahuan ibu-ibu anggota 'Aisyiyah tersebut tentang sejarah kota Surakarta. Wawancara dengan metode tersebut juga dilakukan untuk memberikan pengetahuan awal kepada mereka tentang keberadaan ibu kota Kerajaan Mataram dan Kasunanan Surakarta yang kini menjadi Kota Surakarta. Ibu-ibu yang diwawancarai menyatakan bahwa mereka tidak tahu sejarah Kota Surakarta yang menjadi tempat tinggal mereka. Akibatnya, ketika diajukan pertanyaan selanjutnya tentang bagian mana dari Kota Surakarta yang ingin ditampilkan sebagai materi pendidikan warisan budaya 4.0 bagi warga 'Aisyiyah, mereka tidak dapat menjawab. Akan tetapi, mereka merasa senang dengan rencana pembuatan webpage ini dan mendukung pelaksanaan program pendidikan warisan budaya 4.0. Oleh karena itu, mereka menyerahkan kepada tim pengabdian masyarakat dari Fakultas Ilmu Budaya, Universitas Gadjah Mada untuk menentukan fokus konten pendidikan warisan budaya yang dirancang ini.

Ketidaktahuan warga 'Aisyiyah Kota Surakarta terhadap keberadaan warisan budaya dan sejarah Kota Surakarta sangat memprihatinkan sebab hal tersebut merefleksikan kesadaran mereka terhadap warisan budaya Kota Surakarta. Apabila kondisi tersebut tidak ditindaklanjuti, akan mengancam keberlangsungan warisan budaya yang langka serta tidak dapat diperbarui keberadaannya. Apabila warisan budaya rusak atau bahkan punah, hal tersebut akan merugikan generasi mendatang. Mereka akan kehilangan warisan budaya yang memiliki nilai sejarah, budaya, dan pengetahuan yang tinggi. Hal ini mengkhawatirkan karena dapat berimbas pada hilangnya kebanggaan serta identitas mereka sebagai warga Kota Surakarta yang memiliki budaya tinggi pada masa lampau.

\section{Tabap Pelaksanaan}

Pada tahap ini, tim pengabdian masyarakat mengadakan diskusi intern. Diskusi tersebut dilakukan untuk menentukan warisan budaya yang akan dijadikan sebagai konten pendidikan cagar budaya pada webpage Lembaga Kebudayaan. Hasil diskusi menetapkan wilayah dengan nilai sejarah yang tertinggi bagi Kota Surakarta, yaitu Keraton Surakarta dan sekitarnya karena dahulu pernah menjadi ibu kota Kerajaan Surakarta. Keberadaan ibukota tersebut penting untuk diungkap karena dari wilayah inilah Kota Surakarta yang kini memiliki luas kurang lebih $24 \mathrm{~km}^{2}$ berawal. Hasil diskusi tersebut ditindaklanjuti dengan melakukan survei lapangan di Surakarta pada 27-28 Juni 2019.

Fokus survei pada saat itu adalah bagian depan Keraton Kasunanan Surakarta, Museum Keraton, alun-alun utara, dan Masjid Agung Surakarta. Bagian dalam keraton tidak disurvei karena pada saat itu tertutup untuk umum. Data yang dikumpulkan pada survei berupa foto, video, dan informasi terkait warisan budaya diperoleh dari wawancara ataupun studi pustaka.

Pada saat survei berlangsung, diskusi dengan narasumber, yakni dosen di bidang Pendidikan IT dari Universitas Muhammadiyah Surakarta (UMS), Irma Yuliana, S.T., M.M. dan mahasiswa S-1 Pendidikan IT dari UMS, Arif Rahmanto, yang bertindak sebagai webdesigner, tetap dilakukan untuk menyamakan persepsi tentang hal yang ingin dikerjakan. Dalam diskusi tersebut diputuskan bahwa fokus konten webpage adalah bagian-bagian yang menarik dan unik dari Keraton Kasunanan Surakarta serta Masjid 
Agung Surakarta. Bagian-bagian yang dimaksud adalah menara yang ada di Keraton Surakarta, yang disebut dengan Panggung Sanggabuwana. Panggung Sanggabuwana adalah satu-satunya menara yang terletak dalam sebuah keraton di Jawa. Bagian lain dari kawasan Keraton Kasunanan Surakarta yang dijadikan konten webpage adalah alun-alun. Ada dua alun-alun yang ada di kawasan tersebut, namun alun-alun yang dijadikan sebagai konten webpage adalah Alun-Alun Lor. Masjid Agung Surakarta juga merupakan warisan budaya yang menjadi konten webpage. Beberapa bagian pada Masjid Agung Surakarta yang dijadikan konten adalah façade, menara, atap, ukiran pada pintu masuk masjid, dan kolam yang ditampilkan pada foto serta narasi sebagai bukti adanya pengaruh Islam di Kota Jawa. Video yang menjadi konten webpage memaparkan hubungan antara Keraton Kasunanan Surakarta dan Masjid Agung Surakarta. Agar webpage menjadi lebih menarik, didiskusikan pula judul dari konten yang ada pada webpage.

\section{Surakarta: Pesona Kota Jawa Islam}

Webpage pada pengabdian ini diberi judul "Surakarta: Pesona Kota Jawa Islam”. Judul tersebut dipilih karena keunikan sejarah; keindahan seni, baik berupa arsitektur bangunan maupun ukirnya; serta filosofi yang ada pada elemen bangunan di Kota Surakarta sebagai kota Jawa yang mendapat pengaruh Islam.

Sesuai dengan sasaran dari webpage ini, yaitu ibu-ibu warga 'Aisyiyah di Kota Surarakarta, maka bahasa yang digunakan dalam webpage adalah bahasa ilmiah populer. Hal tersebut dilakukan agar pendidikan yang disampaikan mudah dipahami oleh masyarakat.

Untuk menjamin kesesuaian antara webpage yang sudah didesain oleh webdesigner dengan tujuan dari pengabdian masyarakat, dilakukan review oleh tim pengabdian masyarakat. Selanjutnya, webpage yang telah direvisi kemudian diunggah. Akan tetapi, kuota konten webpage yang dirancang dalam pengabdian masyarakat ini sangat besar sehingga tidak dapat dimuat secara langsung pada website Pimpinan Daerah 'Aisyiyah Kota Surakarta tempat webpage Lembaga Kebudayaan berada. Hal tersebut kemudian diatasi dengan membuat website Lembaga Kebudayaan Pimpinan Daerah 'Aisyiyah Kota Surakarta yang baru dan mandiri. Website tersebut dihubungkan dengan website Pimpinan Daerah 'Aisyiyah Kota Surakarta, demikian pula sebaliknya. Pada tahap ini diperlukan kerja sama dengan webadmin Pimpinan Pusat 'Aisyiyah sebagai pihak yang memiliki website 'Aisyiyah se-Indonesia serta peng-input data atau admin dari website Pimpinan Daerah 'Aisyiyah Kota Surakarta untuk membuat link dari website Pimpinan Daerah 'Aisyiyah Surakarta ke website Lembaga Kebudayaan Pimpinan Daerah 'Aisyiyah Kota Surakarta.

Pembuatan website dengan konten webpage yang berkaitan dengan warisan budaya pada Kota Surakarta ini diharapkan dapat memberikan manfaat yang sebesarbesarnya bagi Lembaga Kebudayaan Pimpinan Daerah 'Aisyiyah Kota Surakarta untuk menjalankan program-programnya. Tidak hanya itu, website tersebut juga diharapkan dapat meningkatkan pemahaman warga 'Aisyiyah yang tinggal di Kota Surakarta terhadap keberadaan warisan budaya sebagai bagian dari kehidupan manusia pada masa lampau, kini, dan mendatang. Hal ini sesuai dengan tujuan arkeologi, yaitu memberikan sumbangan dalam merekonstsruksi kehidupan manusia pada masa lampau 
melalui tinggalannya, baik berupa benda bergerak maupun bangunan serta lanskap atau bentang lahan (Sedyawati, 2012:6).

\section{Hasil/Output Kegiatan}

Luaran dari kegiatan ini adalah webpage yang dapat diakses pada tautan http:// lkpdasurakarta.com/. Tampilan dari webpage yang telah selesai dapat ditampilkan seperti pada gambar berupa tangkapan layar di bawah ini.

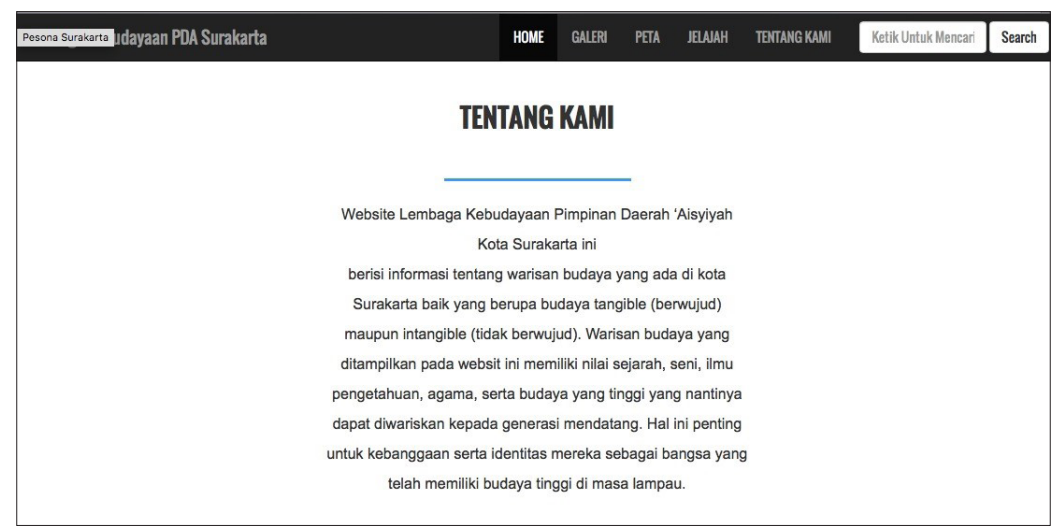

Gambar 1. Tampilan Webpage yang Berisi Keterangan Singkat mengenai Website, Konten, serta Tujuan Website.

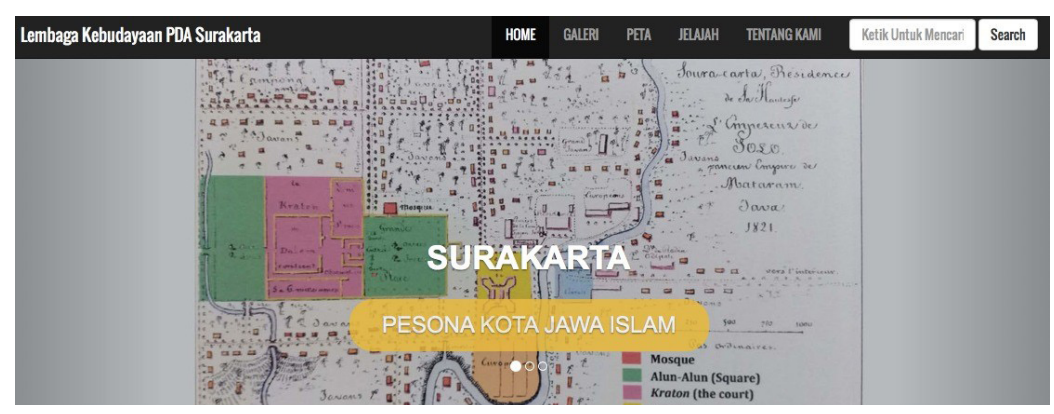

Gambar 2. Peta Tertua Kota Surakarta sebagai Latar Belakang Webpage.

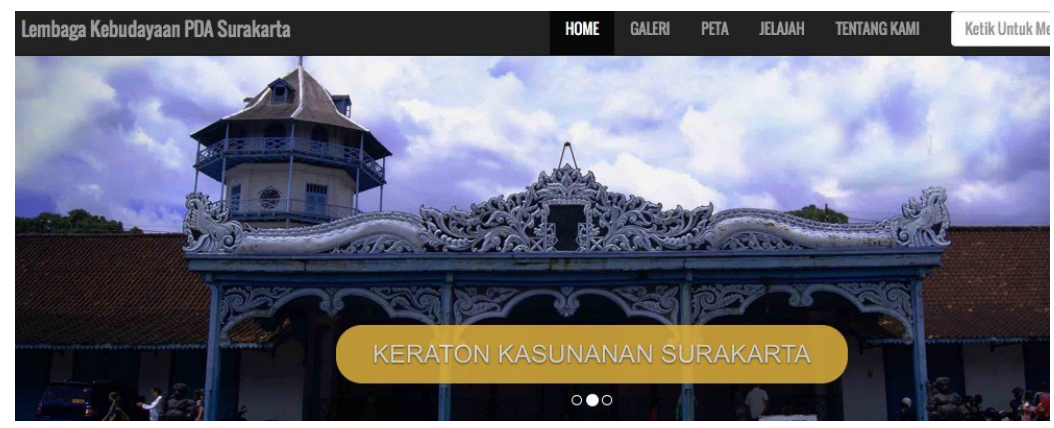

Gambar 3. Keraton Surakarta sebagai Latar Belakang Webpage. 


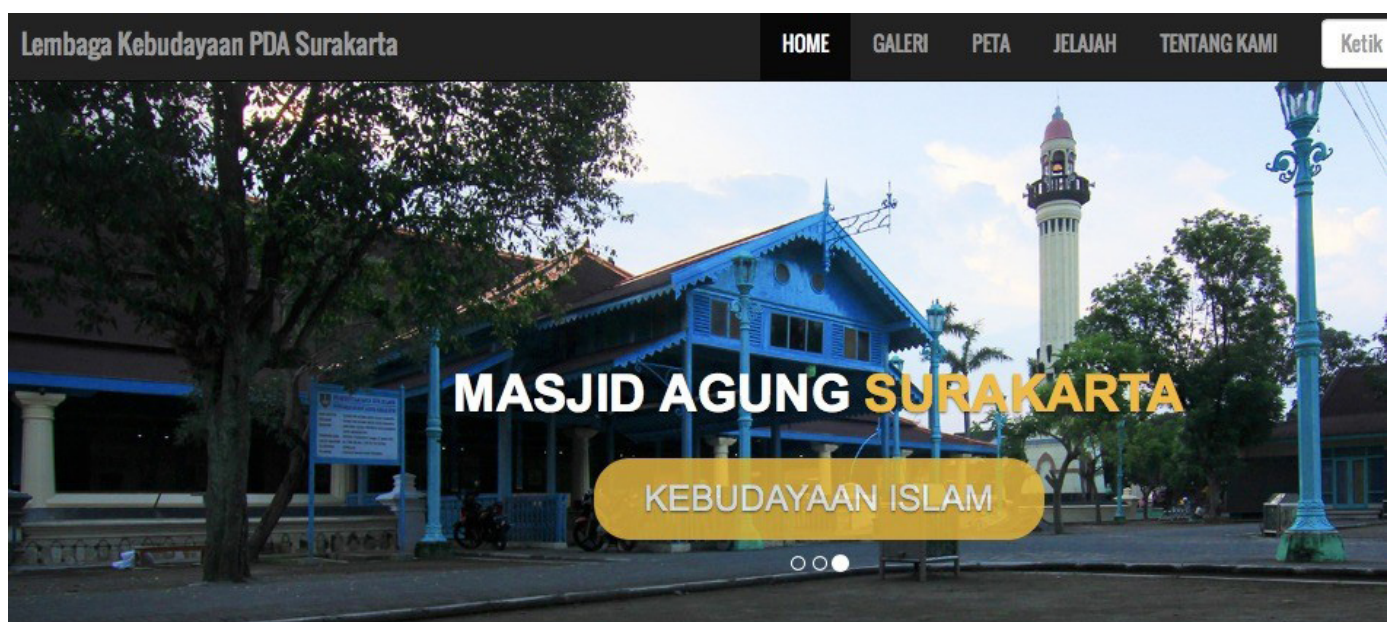

Gambar 4. Masjid Agung Surakarta sebagai Latar Belakang Webpage.

Webpage di atas diberi latar belakang foto tiga objek peninggalan berupa sebuah peta sketsa tertua yang digambar oleh orang Prancis bernama Hubert Joseph Jean Lambert Ridder de Stuers pada 1821 (Bruggen dan Wassing, 1998:154). Lihat pada Gambar 2. Bangunan-bangunan bersejarah lainnya yang ditampilkan sebagai latar belakang adalah Keraton Surakarta (lihat Gambar 3) dan Masjid Agung Surakarta (lihat Gambar 4). Tiga foto tersebut dapat berubah secara otomatis atau manual atas pertimbangan estetis tampilan.

Selain tampilan tersebut, halaman muka webpage juga dilengkapi dengan beberapa menu seperti galeri, peta, dan jelajah. Untuk edisi awal, bagian galeri akan memunculkan beberapa objek peninggalan sejarah berupa bangunan-bangunan yang berada di kompleks keraton Kasunanan Surakarta yang di-link-kan dengan akun Instagram Pessona Surakarta.

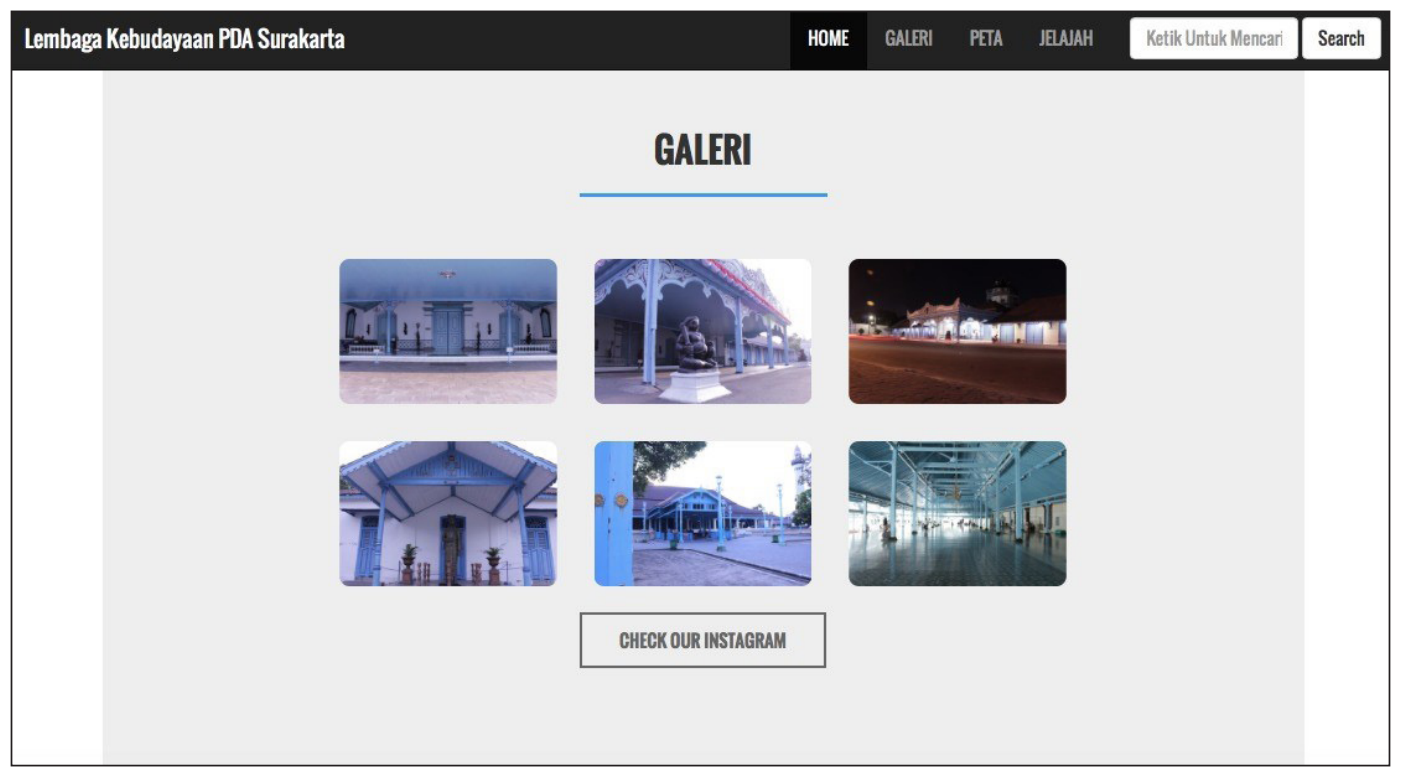

Gambar 5. Menu Galeri pada webpage berisi foto beberapa bagian dari Keraton Surakarta dan Masjid Agung Surakarta. 


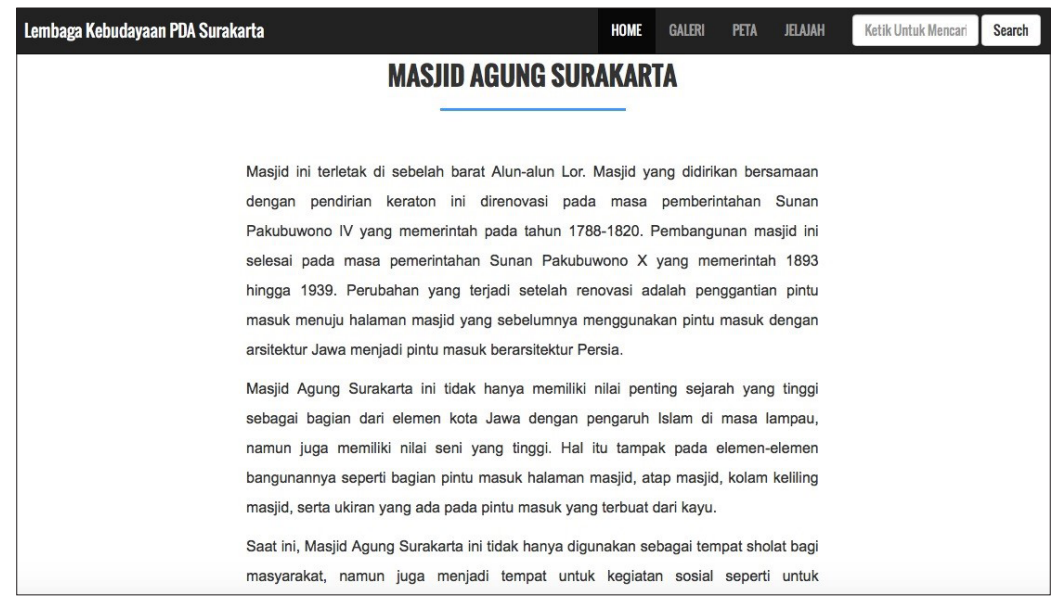

Gambar 6. Keterangan yang menyertai gambar yang dipilih oleh pengguna webpage.

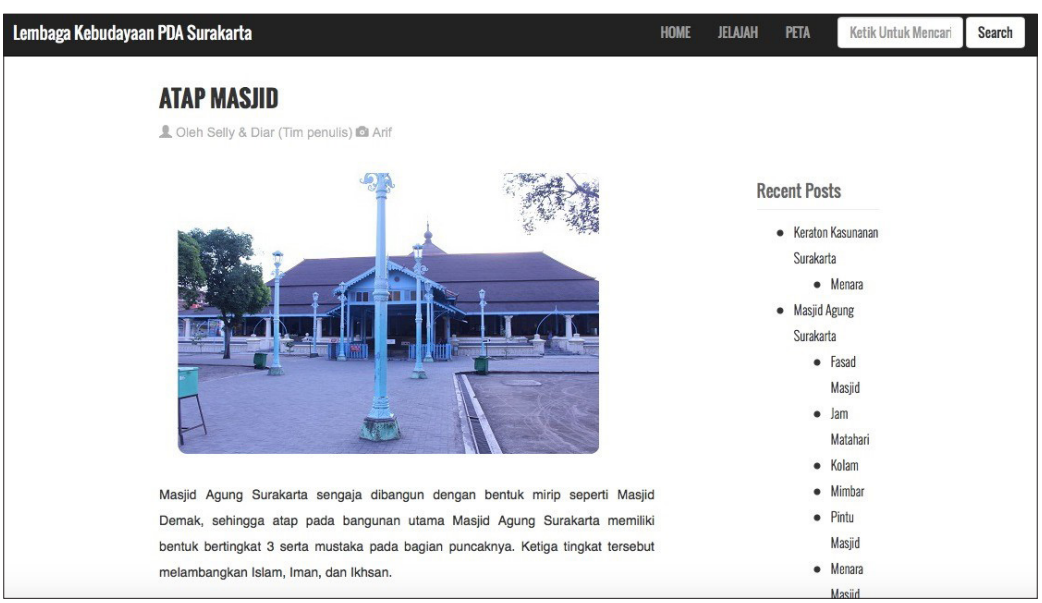

Gambar 7. Informasi lebih detail terkait dengan objek bangunan yang muncul pada galeri.

Selain tampilan yang memuat informasi beberapa objek bangunan bersejarah, webpage ini juga menampilkan peta yang memberi informasi keletakan dari objek-objek tersebut.

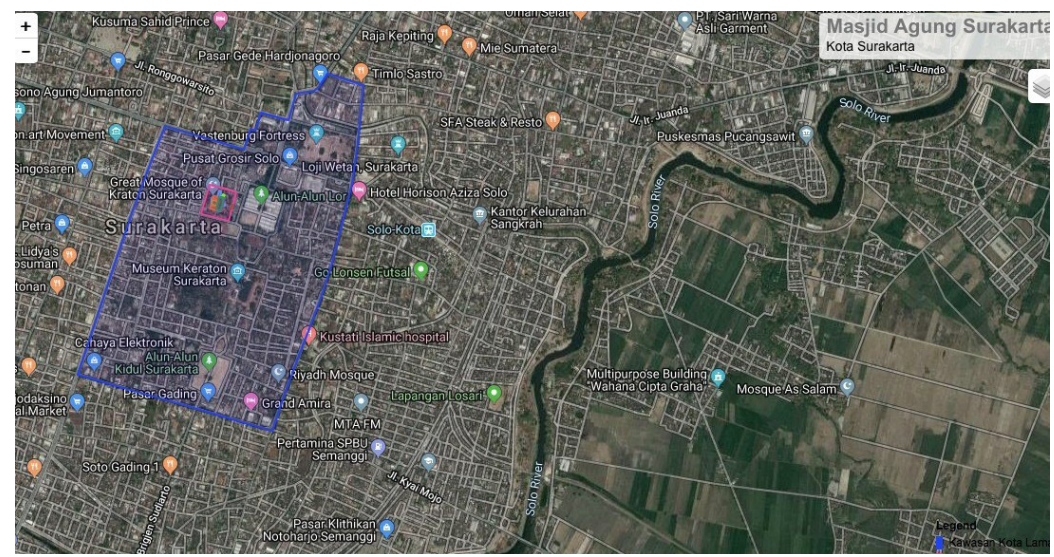

Gambar 8. Letak objek bangunan yang ditampilkan dalam webpage (di dalam garis biru). 


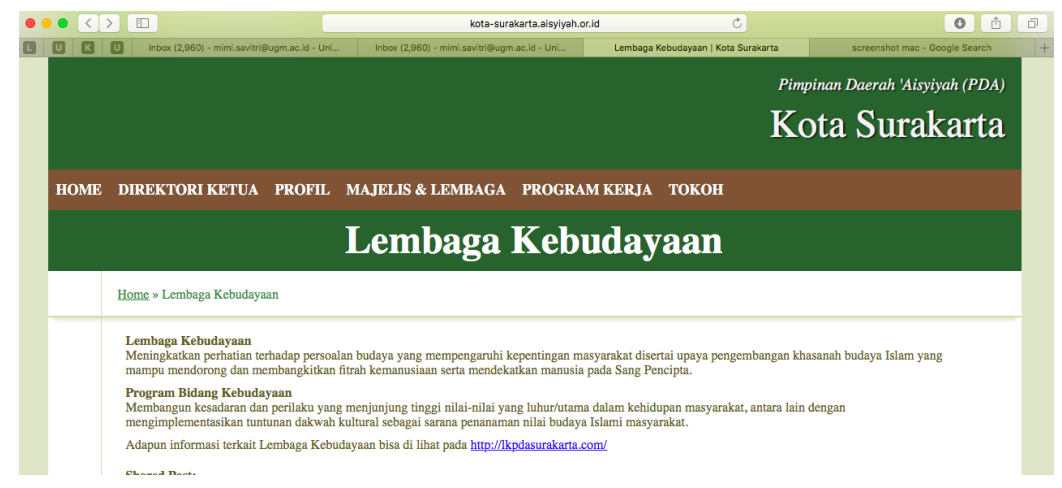

Gambar 9. Website Lembaga Kebudayaan yang baru dan mandiri dengan alamat http://kpdasurakarta.com/ yang ditampilkan pada webpage Lembaga Kebudayaan yang ada pada website Pimpinan Daerah 'Aisyiyah Kota Surakarta.

\section{Diseminasi}

Website Lembaga Kebudayaan yang didesain ini telah didesiminasikan sebanyak tiga kali. Diseminasi pertama dilakukan pada rapat koordinasi program kerja Lembaga Kebudayaan Pimpinan Daerah 'Aisyiyah se-Solo Raya pada 25 Agustus 2019. Tanggapan yang diberikan oleh peserta rapat adalah tanggapan positif sebab para peserta berniat mengajukan permohonan kepada tim pengabdian untuk membina mereka dalam membuat website, sebagaimana website Lembaga Kebudayaan Pimpinan Daerah Kota Surakarta.

Diseminasi kedua dilakukan pada rapat koordinasi kegiatan 'Aisyiyah se-Surakarta pada 29 Agustus 2019. Pada saat itu, para peserta yang terdiri atas pimpinan 'Aisyiyah Kota Surakarta tingkat cabang diminta untuk membuka website Lembaga Kebudayaan Pimpinan Daerah 'Aisyiyah bersama-sama. Beberapa peserta tampak antusias untuk melihat konten website tersebut. Namun, karena keterbatasan waktu, kesan mereka terhadap website tersebut belum dapat diketahui. Diseminasi ketiga dilakukan melalui grup WhatsApp "Komunitas 'Aisyiyah SKA" pada 29 Agustus 2019. Hanya satu dari 37 anggota grup yang merespons dengan menyatakan bahwa ia telah membuka website tersebut.

Diseminasi yang dilakukan tersebut masih berupa tahap awal. Pada 2020 mendatang akan diselenggarakan pengabdian masyarakat lanjutan untuk mengetahui feedback warga 'Aisyiyah terhadap website tersebut, yang dilakukan secara langsung ataupun virtual dengan cara melengkapi website dengan menu jumlah pengunjung dan kolom komentar.

\section{Penutup}

Webpage pada website Lembaga Kebudayaan Pimpinan Daerah 'Aisyiyah Kota Surakarta ini didesain untuk memenuhi kebutuhan informasi mengenai warisan budaya di kota dengan tujuan mendidik warga 'Aisyiyah Kota Surakarta agar paham terhadap tinggalan budayanya. Dua bangunan utama yang berada di ibukota Kerajaan atau Kasunanan Surakarta seperti Keraton Surakarta dan Masjid Agung Surakarta dipilih sebagai konten pendidikan bagi webpage karena memiliki nilai kesejarahan, budaya, dan pengetahuan yang tinggi.

Pengetahuan dan pemahaman warga 'Aisyiyah yang meningkat terkait dengan 
peninggalan bangunan-bangunan bersejarah di Kota Surakarta ini diharapkan dapat menumbuhkan kesadaran mereka terhadap warisan budaya sebagai bagian dari kehidupan mereka. Selanjutnya, kesadaran itu penting untuk mendukung upaya pemerintah dalam melestarikan warisan budaya yang tidak hanya berguna untuk generasi saat ini, namun juga generasi mendatang.

Tindak lanjut dari pengabdian ini adalah melakukan diseminasi dan evaluasi terhadap website Lembaga Kebudayaan Pimpinan Daerah 'Aisyiyah Kota Surakarta. Untuk menjaga kelangsungan website tersebut, perlu diangkat webadmin yang bertanggung jawab terhadap kelangsungannya. Kerja sama dengan admin website Pimpinan Daerah 'Aisyiyah Kota Surakarta sangat diperlukan karena website Lembaga Kebudayaan yang telah dikerjakan pada pengabdian masyarakat ini merupakan bagian dari website Pimpinan Daerah 'Aisyiyah Kota Surakarta. Selanjutnya, program pengabdian masyakarat ini diharapkan dapat menginspirasi Lembaga Kebudayaan Pimpinan Daerah 'Aisyiyah Kota Surakarta dan majelis-majelis lainnya pada Pimpinan Daerah 'Aisyiyah Kota Surakarta untuk membuat konten-konten pendidikan yang bermanfaat bagi masyarakat, baik bagi masyarakat 'Aisyiyah Kota Surakarta maupun masyarakat luas.

\section{Ucapan Terima Kasih}

Ucapan terima kasih disampaikan kepada Fakultas Ilmu Budaya Universitas Gadjah Mada atas dana yang diberikan demi terlaksananya pengabdian masyarakat ini. Ucapan terima kasih juga disampaikan kepada Pimpinan Daerah 'Aisyiyah Kota Surakarta atas kerja sama yang diberikan dalam hal perizinan. Terima kasih kepada Lembaga Kebudayaan Pimpinan Daerah 'Aisyiyah Kota Surakarta atas waktu yang diberikan untuk melakukan wawancara pada saat pengabdian ini dikerjakan. Terima kasih diucapkan kepada Irma Yuliana, S.T., M.M. atas informasi yang diberikan terkait dengan pendidikan Teknologi Informatika, Eka Indarto, M.T. atas diskusi-diskusi serta $e$-book yang dikirimkan, yang menginspirasi terlaksananya pengabdian masyarakat terkait dengan pendidikan pada era digital 4.0 ini.

\section{Daftar Pustaka}

Aucklair, Elizabeth dan Graham Fairclough. (2015). Living Between Past and Future: An Introduction to Heritage and Cultural Sustainability. Oxon: Routledge.

Bandarin, Francesco dan Ron van Oers. (2015). Reconnecting the City The Historic Urban Landscape Approach and the Future of the Urban Heritage. West Sussex: John Wiley \& Sons.

Bruggen, M.P. van dan R.S. Wassing. (1998). Djogja en Solo. Purmerend: Asia Maior. Darmosugito. (1956). Kota Yogyakarta 200 Tahun. Yogyakarta: tanpa nama penerbit.

Hadirin, Hj. Rodhiyah dkk. (2001). Sejarah dan Langkah Aisyiyah Kota Surakarta. Surakarta: Pimpinan Daerah Aisyiyah Kota Surakarta.

Morgan, Colleen dan Stuart Eve. (2012). "DIY and Digital Archaeology: What Are You Doing to Participate" dalam World Archaeology, Vol. 44 (4). Open Archaeology. Taylor \& Francis: 521-537.

Putranto, Andi dan Dwi Pradnyawan. (2018). "Model Penilaian Kriteria Bangunan 
Cagar Budaya Berbasis Analisis Quantitatif Berjenjang Dengan Faktor Pembobot: Kajian Bangunan Cagar Budaya di Kota Solo" dalam Naditira Widya, Volume 12, No. 2, hlm. 159-172. Banjarmasin : Balai Arkeologi Banjarmasin.

Putranto, Andi. (2016). "Metode Pengukuran Cepat Ukuran Luasan Bangunan Cagar Budaya di Kota Solo (Sebuah Uji Perbandingan Pengukuran)”. Laporan Penelitian. Yogyakarta: Fakultas Ilmu Budaya UGM.

Savitri, Mimi. (2015). "Sustaining The Layout of Javanese City Centre 1745-1942: The Embodiment of The Aunan's Power in Surakarta”. Disertasi. London: SOAS, University of London.

Sedyawati, Edi. (2012). "Arkeologi Membidik Sasaran yang Senantiasa Bergerak" dalam Rahardjo, Supratikno (ed.). Arkeologi untuk Publik. Jakarta: Ikatan Ahli Arkeologi Indonesia.

Simanjuntak, Truman. (2012). "Arkeologi dan Pembangunan Karakter Bangsa” dalam Rahardjo, Supratikno (ed.). Arkeologi untuk Publik. Jakarta: Ikatan Ahli Arkeologi Indonesia.

Undang-Undang Republik Indonesia Nomor 11 Tahun 2010 Tentang Cagar Budaya.

\section{Daftar Laman}

Aosgi. (2018). "Wujudkan Solo Smart City, Pemkot Siapkan Integrasi Aplikasi”. http:// surakarta.go.id/?p=12070 diunduh 19 Oktober 2019.

http://www.muhammadiyah.or.id/id/content-199-det-aisyiyah.html diunduh 6 Februari 2019.

http://kota-surakarta.aisyiyah.or.id/id/page/lembaga-kebudayaan.html diunduh 6 Februari 2019. 